\title{
Using the interplay of magnetic guidance and controlled TGF- $\beta$ release from protein-based nanocapsules to stimulate chondrogenesis
}

This article was published in the following Dove Press journal: International Journal of Nanomedicine

\author{
Chih-Sheng Chiang' \\ Jian-Yi Chen' \\ Min-Yu Chiang' \\ Kai-Ting Hou' \\ Wei-Ming $\mathrm{Li}^{\prime}$ \\ Shwu-Jen Chang ${ }^{2}$ \\ San-Yuan Chen' \\ 'Department of Materials Science \\ and Engineering, National Chiao \\ Tung University, Hsinchu, Taiwan; \\ ${ }^{2}$ Department of Biomedical \\ Engineering, I-Shou University, \\ Kaohsiung, Taiwan
}

\begin{abstract}
Introduction: Stimulating the proliferation and differentiation of chondrocytes for the regeneration of articular cartilage is a promising strategy, but it is currently ineffective. Although both physical stimulation and growth factors play important roles in cartilage repair, their interplay remains unclear and requires further investigation. In this study, we aimed to clarify their contribution using a magnetic drug carrier that not only can deliver growth factors but also provide an external stimulation to cells in the two-dimensional environment.

Materials and methods: We developed a nanocapsule (transforming growth factor- $\beta 1$ [TGF- $\beta 1$ ]loaded magnetic amphiphilic gelatin nanocapsules [MAGNCs]; TGF- $\beta 1 @$ MAGNCs) composed of hexanoic-anhydride-grafted gelatin and iron oxide nanoparticles to provide a combination treatment of TGF- $\beta 1$ and magnetically induced physical stimuli. With the expression of Arg-Gly-Asp peptide in the gelatin, the TGF- $\beta 1 @$ MAGNCs have an inherent affinity for chondrogenic ATDC5 cells. Results: In the absence of TGF- $\beta 1$, ATDC 5 cells treated with a magnetic field show significantly upregulated Col2a1 expression. Moreover, TGF- $\beta 1$ slowly released from biodegradable TGF- $\beta 1 @$ MAGNCs further improves the differentiation with increased expression of Col2al and Aggrecan. Conclusion: Our study shows the time-dependent interplay of physical stimuli and growth factors on chondrogenic regeneration, and demonstrates the promising use of TGF- $\beta 1 @$ MAGNCs for articular cartilage repair.
\end{abstract}

Keywords: physical stimuli, chondrogenic regeneration, TGF- $\beta 1$, amphiphilic gelatin, combination stimuli

\section{Introduction}

Articular cartilage (AC) is a specialized tissue that can be used to facilitate the transmission of loads, but tissue repair has been a medical challenging because of the low self-repairing capacity of cartilage resulting from the lack of a neural, vascular, and lymphatic network. ${ }^{1-3}$ Although current techniques including microfracture, autologous chondrocyte implant (ACI), and matrix-induced ACI have demonstrated an acceptable functional outcome, the controversial therapeutic benefits due to immature neotissue after implantation and the long recovery time have left plenty of room for improvement. ${ }^{4,5}$ Therefore, novel strategies such as cell-based or cell-free 3-dimensional engineered tissue that aim to regenerate functional neotissue have received much attention. Of note, exogenous chondrocyte stimuli including growth factors and mechanical stimulation are widely used to promote the maturation of the cells. Additionally, using biomarkers, such as lubricin and $\beta$-Defensin, to evaluate the repair of cartilage lesions in patients with osteoarthritis (OA) has received much attention. ${ }^{6,7}$ Recent in vivo and in vitro results have demonstrated exogenous chondrocyte stimuli including
Correspondence: San-Yuan Chen Department of Materials Science and Engineering, National Chiao Tung University, No I00I, Ta-Hsueh Road Hsinchu 300 I0, Taiwan

Tel +8863 57| 2I2I ext 318I8

Email sanyuanchen@mail.nctu.edu.tw

Shwu-Jen Chang

Department of Biomedical Engineering, I-Shou University, Yanchao Campus,

No 8, Yida Road, Jiaosu Village,

Yanchao District, Kaohsiung

82445, Taiwan

Email sjchang@isu.edu.tw 
growth factors and mechanical stimulation can promote the maturation of the cells along with the change of biomarkers such as increased lubricin expression in aged rats. ${ }^{8}$

As we know, the transforming growth factor- $\beta$ (TGF- $\beta$ ) family members, especially TGF- $\beta 1$ and TGF- $\beta 3$, are widely applied to autologous chondrocytes or mesenchymal stem cells (MSCs) to maintain the phenotype and induce the production of extracellular matrix. TGF- $\beta 1$ also regulates homeostasis in cartilage during treatment. ${ }^{9-12}$ However, an effective delivery of growth factor is crucial to induce the cellular signaling required to initiate differentiation. Therefore, bioactive microspheres derived from materials such as hyaluronan, ${ }^{10}$ alginate, ${ }^{13}$ chitosan, ${ }^{12}$ and chondroitin sulfate ${ }^{14}$ are designed to sustain the phenotype and achieve finely controlled delivery of signaling agents.

In addition, mechanical loading of AC can further stimulate the metabolism of chondrocytes and induce mechanical signals to tune the biochemical changes. Musumeci et al ${ }^{15}$ proposed mechanobiology to explain the benefits of the mechanical stimulation on AC based on the concept that physical forces and changes in cell or tissue mechanics contribute to development, physiology, and disease. Multiaxial loads such as compression, shear, and synergistic forces can enhance the chondrogenic response of MSCs including collagen type II and aggrecan expression of MSC-derived chondrocytes, particularly for asymmetrical seeding of MSCs in scaffolds. ${ }^{16,17}$ Son et a $1^{18}$ demonstrated that magnetic particles could enhance the chondrogenic commitment of bone marrow-derived MSCs via magnetic force. Although both physical stimuli and growth factors play pretty important roles in cartilage repair, their cooperative interaction in chondrogenesis is largely unexplored. Moreover, the attachment of transplanted cells to the defect in AC can determine the fate of transplantation. Therefore, the identification of therapeutic approaches that overcome these obstacles is urgently needed.

Here, we developed a gelatin-based magnetic nanomedicine that can simultaneously provide physical and chemical stimulation for cell therapy, and further achieve cell retention at desired sites for robust and prolonged treatment. Gelatin has a lower antigenicity than animal collagen, and no toxicity was reported for its degraded by-products. Moreover, the Arg-Gly-Asp peptide (RGD) in the structure of gelatin produces an increased affinity for chondrocytes. ${ }^{19}$ By grafting hydrophobic components to gelatin, amphiphilic gelatin (AG) can be synthesized to form core-shell magnetic AG nanocapsules (MAGNCs) via emulsification in the presence of hydrophobic iron oxide nanoparticles.

With encapsulation of TGF- $\beta 1$ in the core, a sustained controlled release of TGF- $\beta 1$ via the gradual degradation of the nanostructure can be achieved. To assess the interplay of physical stimuli and TGF- $\beta 1$ on chondrogenesis, we used TGF- $\beta 1$-loaded MAGNCs (TGF- $\beta 1 @$ MAGNCs). In addition, we selected the ATDC5 cell line as an in vitro cell model. ${ }^{20}$ TGF- $\beta 1 @$ MAGNCs facilitated RGD on the surface to rapidly associate with ATDC5, and the magnetized ATDC5 cells were effectively guided by a magnetic field (MF) to the desired site for cell retention. The results demonstrate that while TGF- $\beta 1$ was ineffective at stimulating chondrogenesis within 7 days, MAGNCs with magnetic treatment $($ MAGNCs $+\mathrm{M})$ showed a 3.2-fold increase in expression of Col2a1. The combination of TGF- $\beta 1 @$ MAGNCs with magnetic treatment (TGF- $\beta 1 @$ MAGNCs + M) significantly promoted the upregulation of Col2a1 and Aggrecan expression compared with TGF- $\beta 1 @$ MAGNCs and MAGNCs + M over a 14-day incubation period. In addition, sustained expression of Col2a1 and enhanced sulfated glycosaminoglycan (sGAG) secretion demonstrate that cells are undergoing chondrogenesis. Overall, protein-based MAGNCs can achieve rapid cell association, combined stimulation, and cell retention, resulting in a promising nanoplatform for cell-based $\mathrm{AC}$ regeneration.

\section{Materials and methods Preparation of AG}

Type A 300 bloom gelatin powder (from porcine skin, $0.75 \mathrm{~g}$ ) was dissolved in deionized water $(10 \mathrm{~mL})$, and sodium hydroxide solution $(0.25 \mathrm{~mL}, 1 \mathrm{~N})$ was added to the gelatin solution with magnetic stirring at $70^{\circ} \mathrm{C}$ overnight (Supplementary materials). Here, the molecular weight of gelatin is $87,500 \mathrm{Da}$, which is smaller than that of collagen fiber (300,000 Da). Assuming the RGD motif encoded in collagen was not damaged after decomposing into gelatin, the RGD amount ratio can be calculated using the formula:

$$
\begin{aligned}
& \text { RGD amount ratio of gelatin }=87,500 \times \frac{7}{300,000} \\
& \sim 2 \text { RGD motifs/each gelatin }
\end{aligned}
$$

Next, the gelatin solution was mixed by stirring with ethanol $(95 \%, 7.5 \mathrm{~mL})$ and hexanoic anhydride $(0.5 \mathrm{~mL})$ for $4 \mathrm{~h}$. The graft rate of hexanoyl group could be analyzed using 2,4,6-trinitrobenzenesulfonic acid reagent to determine the content of free amino groups remaining in the AG. After the reaction, the mixed samples were allowed to cool down to room temperature and the $\mathrm{pH}$ was adjusted to $\mathrm{pH}=7.4$ using dilute sodium hydroxide. The final solutions were collected using dialysis tubing cellulose membrane (molecular weight 
cut $=14,000$ ) in ethanol for $48 \mathrm{~h}$. The gel was then collected and dried in the oven at $60^{\circ} \mathrm{C}$ and ground into powder.

\section{Synthesis of superparamagnetic iron oxide nanoparticles $\left(\mathrm{Fe}_{3} \mathrm{O}_{4}\right)$}

$\mathrm{Fe}_{3} \mathrm{O}_{4}$ were synthesized according to protocol of Sun et $\mathrm{al}^{21}$ In brief, $\mathrm{Fe}(\mathrm{acac})_{3}(2 \mathrm{mmol}), 1,2$-hexadecanediod (10 mmol), oleic acid $(6 \mathrm{mmol})$, and olecylamine $(6 \mathrm{mmol})$ were mixed in a 3-necked bottle. The mixture was dissolved in benzyl ether $(20 \mathrm{~mL})$ and refluxed at $100^{\circ} \mathrm{C}$ for $30 \mathrm{~min}$ under the flow of nitrogen. Then, the mixture was heated to $200^{\circ} \mathrm{C}$ for another hour, and heated to $300^{\circ} \mathrm{C}$ for $30 \mathrm{~min}$. After cooling to room temperature, the product was collected by centrifugation at $12,000 \mathrm{rpm}$ for $10 \mathrm{~min}$, and washed with excess ethanol 3 times. The $\mathrm{Fe}_{3} \mathrm{O}_{4}$ was then redispersed and stored in ethanol at $4^{\circ} \mathrm{C}$.

\section{Preparation of MAGNCs}

To prepare MAGNCs, AG was added to deionized water $(2 \mathrm{~mL})$ and mixed with $\mathrm{NaOH}$ solution $(2 \mathrm{~mL}, 0.1 \mathrm{~N})$ at $70^{\circ} \mathrm{C}$ under ultrasonic stimulation until the gelatin was completely dissolved. The solution was then centrifuged at $7,500 \mathrm{rpm}$ for $10 \mathrm{~min}$. The supernatant of the gelatin solution $(0.6 \mathrm{~mL})$ and superparamagnetic iron oxide nanoparticles (SPIOs) $(10 \mathrm{mg})$ in chloroform $(1 \mathrm{~mL})$ were emulsified for 1 min to obtain a water in oil emulsion. Then, another AG solution $(2.4 \mathrm{~mL})$ was added to the emulsion and the secondary emulsion was processed for $1.5 \mathrm{~min}$. The mixture was then stirred and heated to $60^{\circ} \mathrm{C}$ for $40 \mathrm{~min}$ on a hot plate to ensure complete removal of chloroform. The final MAGNC products were washed 3 times using deionized water.

\section{Drug/dye encapsulation}

MAGNCs are hollow nanoparticles with a hydrophilic core and hydrophobic shell in 1 single nanostructure. The water-soluble agent TGF- $\beta 1$ was first dissolved in $A G$ water solution, and the rest of the protocol is described in the "Preparation of MAGNCs" section. In addition, to encapsulate oil-soluble substances such as FITC and CdSe/ $\mathrm{ZnS}$ quantum dots (QDs), the agents were dissolved in chloroform prior to completion of the previously described emulsion process.

\section{Characterization of MAGNCs}

The morphology of MAGNCs was analyzed using scanning electron microscope and transmission electron microscope. The size and the zeta potential of MAGNCs were measured using dynamic light scattering (Beckman Coulter Delsa ${ }^{\mathrm{TM}}$
Nano C particle analyzer, Beckman Coulter, Inc., Brea, CA, USA).

\section{Quantification of recombinant mouse TGF- $\beta$ I}

The recombinant mouse TGF- $\beta 1$ was quantified using the Quantikine ${ }^{\circledR}$ ELISA kit of Mouse/Rat/Porcine/Canine TGF- $\beta 1$ immunoassay (R\&D Systems, Minneapolis, MN, USA). First, all reagents were prepared to include standard dilutions, control, activated samples, and the Assay Diluent RD1-21 (50 $\mu \mathrm{L}$, for cell culture supernatant samples) or Assay Diluent RD1-73 (for serum/plasma samples) in each well. Subsequently, $50 \mu \mathrm{L}$ was added per well to the standard, control, or activated samples, and the plate was tapped gently for 1 minute and covered with adhesive strip. After incubation for $2 \mathrm{~h}$ at room temperature, each well was aspirated and washed with wash buffer $(300 \mu \mathrm{L})$, and the process was repeated 4 times. After the last wash, all remaining wash buffer was removed by aspiration, and then the plate was inverted and blotted with clean paper towels. Next, TGF- $\beta 1$ conjugate $(100 \mu \mathrm{L})$ was added to each well and the plate was covered with a new adhesive strip. After incubation for $2 \mathrm{~h}$ at room temperature, the aspiration/wash step was repeated as described previously. Finally, substrate solution $(100 \mu \mathrm{L})$ was added to each well. To determine the optical density of each well, we used the CLARIOstar microplate reader $(450 \mathrm{~nm})$ to measure the optical density value corresponding to the exact concentration of TGF- $\beta 1$.

\section{Encapsulation and release of TGF- $\beta$ I}

To measure the amount of TGF- $\beta 1$ encapsulation, the TGF- $\beta 1 @$ MAGNC sample was centrifuged at 12,000 rpm for $10 \mathrm{~min}$, and the supernatant $(50 \mu \mathrm{L})$ with nonencapsulated TGF- $\beta 1$ was measured using enzyme-linked immunosorbent assay (ELISA) to calculate the amount of TGF- $\beta 1$ encapsulated in the MAGNCs. To monitor the release of TGF- $\beta 1$ with time, TGF- $\beta 1 @$ MANCs were loaded in the cellulose dialysis membrane $(\mathrm{MWCO}=50 \mathrm{k})$ to separate free TGF- $\beta 1$ $\left(M_{\mathrm{w}}=25.6 \mathrm{k}\right)$ from the MAGNCs, and the dialysis buffer was collected and measured using ELISA test.

\section{Degradation test}

The degradation test was performed using the same method as the drug release test. The small molecular weight of the dialysis tubing cellulose membrane was used to determine the amount of degradant generated in the medium. The AG solution was added to a dialysis tubing cellulose membrane 
with a cut-off molecular weight of 2,000. The solution was dialyzed at $37^{\circ} \mathrm{C}$ and the absorbance of the solution was measured at a wavelength of $280 \mathrm{~nm}$ to determine the amount of degraded gelatin.

\section{ATDC5 cell culture and differentiation}

The ATDC5 cell line was purchased from Sigma-Aldrich Co., (St Louis, MO, USA) and characterized as a chondrogenic cell line for in vitro mode. In addition, the ATDC5 cell line exhibits chondrogenic differentiation compared with other established cell lines (C3H10T1/2 and RJC3.1). ${ }^{22}$ In this experiment, ATDC5 cells were maintained in a 75T culture flask in Dulbecco's Modified Eagle's Medium/F12 with 10\% fetal bovine serum for normal cell culture and passage at $37^{\circ} \mathrm{C}$ in a humidified $\mathrm{CO}_{2}(5 \%)$ incubator. To induce ATDC5 differentiation, culture medium with $1 \%$ ITS liquid media supplement (100×) was added to ATDC5 cells with an MF applied for 14 days.

\section{Cell viability test}

The 3-(4,5-dimethylthiazol-2-yl)-5-(3-carboxymethoxyph enyl)-2-(4-sulfophenyl)-2H-tetrazolium) (MTS) assay was utilized to determine cell viability. Briefly, ATDC5 cells were harvested from the $75 \mathrm{~T}$ culture flask and seeded in 6-well plate $\left(10^{4}\right.$ cell per well). Various concentrations $(0,0.5,1,5$, 10,20 , and $50 \mu \mathrm{g} \mathrm{mL}^{-1}$ of SPIO) of MAGNCs were incubated with ATDC5 cells for 1, 3, 5, and 7 days. After that, cells were incubated with culture medium with $10 \%$ MTS agent for $4 \mathrm{~h}$ and the absorbance was monitored using an ELISA reader at wavelength $490 \mathrm{~nm}$. Cell viability was calculated using Equation 1:

$$
\text { Cell viability }(\%)=\frac{\text { Sample optical density }}{\text { Control optical density }} \times 100 \%
$$

\section{Cell uptake measurement}

ATDC5 cells were incubated with MAGNCs (SPIOs concentration $=20 \mu \mathrm{g} \mathrm{mL}^{-1}$ ) using a 24-well plate. The cells were washed 3 times using phosphate buffer solution (PBS) buffer to remove excess MAGNCs that were not associated with cells. After collecting the cells, aqua regia was mixed in all of the samples and incubated overnight in vials. The Fe content of SPIOs representing the MAGNCs was quantified using inductively coupled plasma mass spectrometry.

\section{Immunofluorescence and flow cytometry}

To observe the cell association, $10^{4}$ ATDC 5 cells were seeded on glass coverslips $(15 \times 15 \mathrm{~mm})$ overnight and incubated with
FITC@MAGNCs $\left(\mathrm{Fe}_{3} \mathrm{O}_{4}\right.$ concentration $\left.=20 \mu \mathrm{g} \mathrm{mL}{ }^{-1}\right)$ in a 6-well plate for 1, 2, 4, 8, 24, and $48 \mathrm{~h}$. The cells were then fixed and stained for microscopy (Carl Zeiss, Thornwood, NY, USA). In addition, ATDC5 cells $\left(5 \times 10^{5}\right)$ were seeded in a 24-well plate overnight and incubated with FITC@ MAGNCs $\left(\mathrm{Fe}_{3} \mathrm{O}_{4}\right.$ concentration $\left.=20 \mu \mathrm{g} \mathrm{mL}{ }^{-1}\right)$ for $1,4,8$, 16 , and $24 \mathrm{~h}$. The cells were then collected for cytometry analysis (Novocyte Flow Cytometer, ACEA Bioscience Inc., San Diego, CA, USA).

\section{Guiding ability of magnetized cells}

ATDC5 cells were incubated with QD-labeled MAGNCs $\left(\mathrm{Fe}_{3} \mathrm{O}_{4}\right.$ concentration $\left.=20 \mu \mathrm{g} \mathrm{mL}^{-1}\right)$ using a $10 \mathrm{~cm}$ dish for $8 \mathrm{~h}$. After washing 3 times using PBS buffer to remove excess MAGNCs, the cells were collected and placed in a 6-well plate. Magnets were put under the plate. The cells were then stained with Alexa Fluor ${ }^{\circledR} 488$ Phalloidin (Thermo Fisher Scientific, Waltham, MA, USA) and DAPI for further observation.

\section{Immunofluorescence staining and Alcian blue stain}

For immunofluorescence staining, the cell samples were incubated with different MAGNC formulations and then harvested at $1,3,5,7,11$, and 14 days, followed by fixation and permeabilization and then blocking with $2 \%$ bovine serum albumin for $1 \mathrm{~h}$. The primary antibodies were then prepared in blocking buffer $(1: 250)$ and incubated with the samples at $4^{\circ} \mathrm{C}$ overnight. After a PBS wash, the secondary antibodies were incubated with the samples for $1.5 \mathrm{~h}$. Finally, the samples were stained with DAPI, and observed under a microscope (Carl Zeiss). The Alcian blue 8GX powder was dissolved in a cosolvent (40\% acetic acid and 60\% ethanol) and stored at $4^{\circ} \mathrm{C}$. Alcian blue staining was completed by incubating fixed-cell samples overnight with Alcian blue solution. After staining, the fixed-samples were washed 3 times with PBS buffer.

\section{Blyscan assay and gene expression}

Detailed information of Blyscan assay for assessing sGAG secretion and gene expression using PCR is available. ${ }^{35,36}$

\section{Statistical analysis}

Results are expressed as mean \pm SD. Two-tailed Student's $t$-test was used to evaluate the significance of the mean differences between the control and the treated group, as noted in each figure legend. A $P$-value $\leq 0.05$ was considered significant. 


\section{Results and discussion \\ Synthesis and characterization of TGF- $\beta I @ M A G N C s$}

Figure 1A depicts the synthesis of TGF- $\beta 1 @$ MAGNCs through a simple double emulsion process using $\mathrm{Fe}_{3} \mathrm{O}_{4}$ and amphiphilic gelatin where assuming the RGD motif encoded in collagen was not damaged after decomposing into gelatin, the RGD amount ratio in gelatin was calculated about $\sim 2$. As shown in Figure S1 (Supplementary materials), to increase the amphiphilicity of the gelatin, Arg on the gelatin macromolecule was partially substituted with different amounts of hexanoic anhydride (HA) molecules. The graft rate of the hexanoyl group was measured to be $69.6 \%$ using 2,4,6-trinitrobenzenesulfonic acid reagent, indicating that there are still $30.4 \%$ free amino groups (or RGD motifs) remaining in the arginine and lysine of the gelatin. The proton nuclear magnetic resonance spectra in Figure S2 (Supplementary materials) illustrate the primitive gelatin molecules and the HA-grafted gelatin (HA-gelatin), indicating the substitution of the amino group with a hexanoyl group. The amphiphilicity and the self-assembly property of the AG has been investigated by Li et al. ${ }^{22}$ Both structural stability and drug loading capability are critical factors for developing a hollow nanostructure.

Different concentrations of $\mathrm{Fe}_{3} \mathrm{O}_{4}$ in the emulsion process can affect the structure. The transmission electron microscopy images in Figure S3 (Supplementary materials) show that hydrophobic $\mathrm{Fe}_{3} \mathrm{O}_{4}$ at concentrations of 3 and $5 \mathrm{mg} \mathrm{mL}^{-1}$ formed solid nanoparticles and partial hollow structure, respectively, while a high concentration of $30 \mathrm{mg} \mathrm{mL}^{-1}$ was too unstable to form the nanoparticles. An appropriate window for forming the hollow structure was located at the $\mathrm{Fe}_{3} \mathrm{O}_{4}$ concentration of $10-20 \mathrm{mg} \mathrm{mL}^{-1}$. Moreover, $\mathrm{a} \mathrm{Fe}_{3} \mathrm{O}_{4}$ concentration of $10 \mathrm{mg} \mathrm{mL}^{-1}$ presented a more homogeneous size distribution of hollow MAGNCs compared with $20 \mathrm{mg} \mathrm{mL}^{-1}$ (Figure $\mathrm{S} 3 \mathrm{C}$ and $\underline{\mathrm{G}}$ ), and was chosen for further experiments.

MAGNCs displayed a collapsed structure in a vacuumed state under scanning electron microscope (Figure 1B and C),

\section{A}
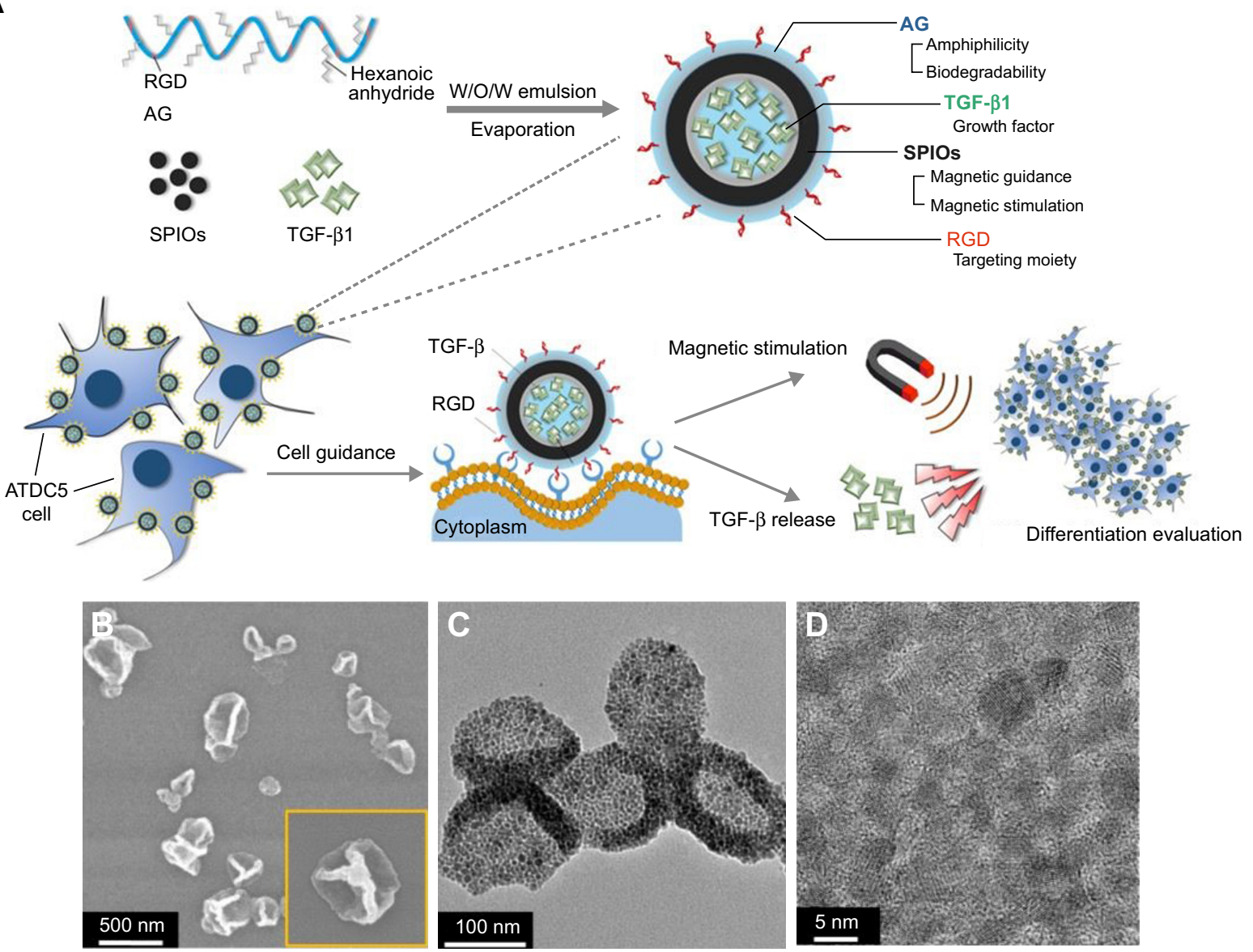

Figure I Graphical illustration and morphology of the synthesis and function of MAGNCs.

Notes: (A) Schematic illustration for the synthesis and hollow structure of TGF- $\beta$ I@MAGNCs. The morphology of MAGNCs was observed using (B) SEM and (C and D) TEM. Abbreviations: AG, amphiphilic gelatin; MAGNCs, magnetic amphiphilic gelatin nanocapsules; RGD, Arg-Gly-Asp peptide; SEM, scanning electron microscope; SPIOs, superparamagnetic iron oxide nanoparticles; TEM, transmission electron microscope; TGF- $\beta$, transforming growth factor- $\beta$; TGF- $\beta$ I@MAGNCs, TGF- $\beta$ I-loaded MAGNCs; W/O/W, water in oil in water. 
and the shell overlay presented a darker contrast as a result of the decreased number of penetrated electrons in transmission electron microscopy as shown in Figure 1D. The mean size and zeta potentials of MAGNCs were measured to be $242.6 \mathrm{~nm}$ (Figure S4; Supplementary materials) and - $24 \mathrm{mV}$, respectively. Furthermore, TGF- $\beta 1$, a growth factor capable of triggering chondrogenesis in MSCs or ATDC5 cells, ${ }^{23,24}$ was encapsulated in MAGNCs to achieve sustained drug release for long-term cell differentiation. Several reports have indicated that the dosage of TGF- $\beta 1$ at $20 \mathrm{ng} \mathrm{mL}^{-1}$ can produce effective differentiation of ATDC5 cells, so it was set as a standard dose in the subsequent experiments. ${ }^{14,23,25,26}$

TGF- $\beta 1$ exhibited a 2 -step release behavior as shown in Figure 2A: 1) a slow release within a 10-day period, where TGF- $\beta 1$ diffused from TGF- $\beta 1 @$ MAGNCs due to the driving force of the concentration gradient and 2) a rapid release at 10-14 days due to degradation of TGF- $\beta 1 @$ MAGNCs. As shown in Figure 2B, a high percentage (74.5\%) of gelatin degraded at day 14 in solution, resulting in an extremely unstable structure (inset in Figure 2B) and subsequently accelerated release of TGF- $\beta 1$. In contrast, when the structure was intact with only 9\% AG degradation, TGF- $\beta 1 @ M A G N C s$ were able to hold TGF- $\beta 1$ during a 3-day incubation.

\section{Cellular association and magnetic guidance of ATDC5 cells}

The long-term cell viability of MAGNC-treated ATDC5 cells is a critical factor for cartilage repair. Therefore, various concentrations $\left(0.5-50 \mu \mathrm{g} \mathrm{mL}^{-1}\right.$ of $\left.\mathrm{Fe}_{3} \mathrm{O}_{4}\right)$ of MAGNCs were incubated with ATDC5 cells for 1, 3, 5, and 7 days to evaluate the cytotoxicity. As shown in Figure S5 (Supplementary materials), the cells incubated with a high $\mathrm{Fe}_{3} \mathrm{O}_{4}$ concentration at 20 and $50 \mu \mathrm{g} \mathrm{mL}^{-1}$ still showed a cell viability that was higher than $90 \%$ for 5 and 7 days incubation, indicating that MAGNCs have negligible cytotoxicity and are compatible with ATDC5 cells in long-term incubation.

Furthermore, ATDC5 cells associated with MAGNCs were magnetized, which enables physical stimuli and magnetic guidance under the application of an external MF. To evaluate the degree of cell magnetization, MAGNCs with various $\mathrm{Fe}_{3} \mathrm{O}_{4}$ concentrations $(0.1,1,5,10,20,50$, and $100 \mu \mathrm{g} \mathrm{mL}^{-1}$ ) were incubated with ATDC5 cells for $24 \mathrm{~h}$, and further received a magnetic selection. As shown in Figure 3A, the ratio of the magnetized cells (cells that can be magnetically selected by MF) increased as the $\mathrm{Fe}_{3} \mathrm{O}_{4}$ concentration increased from 0.1 to $20 \mu \mathrm{g} \mathrm{mL}^{-1}$, while no significant increase was observed for $50 \mu \mathrm{g} \mathrm{mL}^{-1}$. Of note, over $95 \%$ of cells were magnetized at the concentration of $20 \mu \mathrm{g} \mathrm{mL} \mathrm{m}^{-1}$. As the concentration demonstrated negligible cytotoxicity, MAGNCs with $\mathrm{Fe}_{3} \mathrm{O}_{4}$ of $20 \mu \mathrm{g} \mathrm{mL}{ }^{-1}$ were used to investigate the relationship between incubation time and cell magnetization.

Since native RGD on gelatin can act as a ligand with high affinity to cells, ${ }^{19,27,28}$ MAGNCs with RGD exposed on the surface can improve the cell association with ATDC5 cells. As shown in Figure 3B, time-dependent ATDC5 cell association initiated with a high accumulation of MAGNCs (expressed as Fe content) is possibly due to the affinity of MAGNCs toward ATDC5 cells. Intriguingly, the Fe content in ATDC5 did not significantly increase from 6 to $12 \mathrm{~h}$, but $76.6 \%$ of magnetized ATDC5 at $12 \mathrm{~h}$ incubation
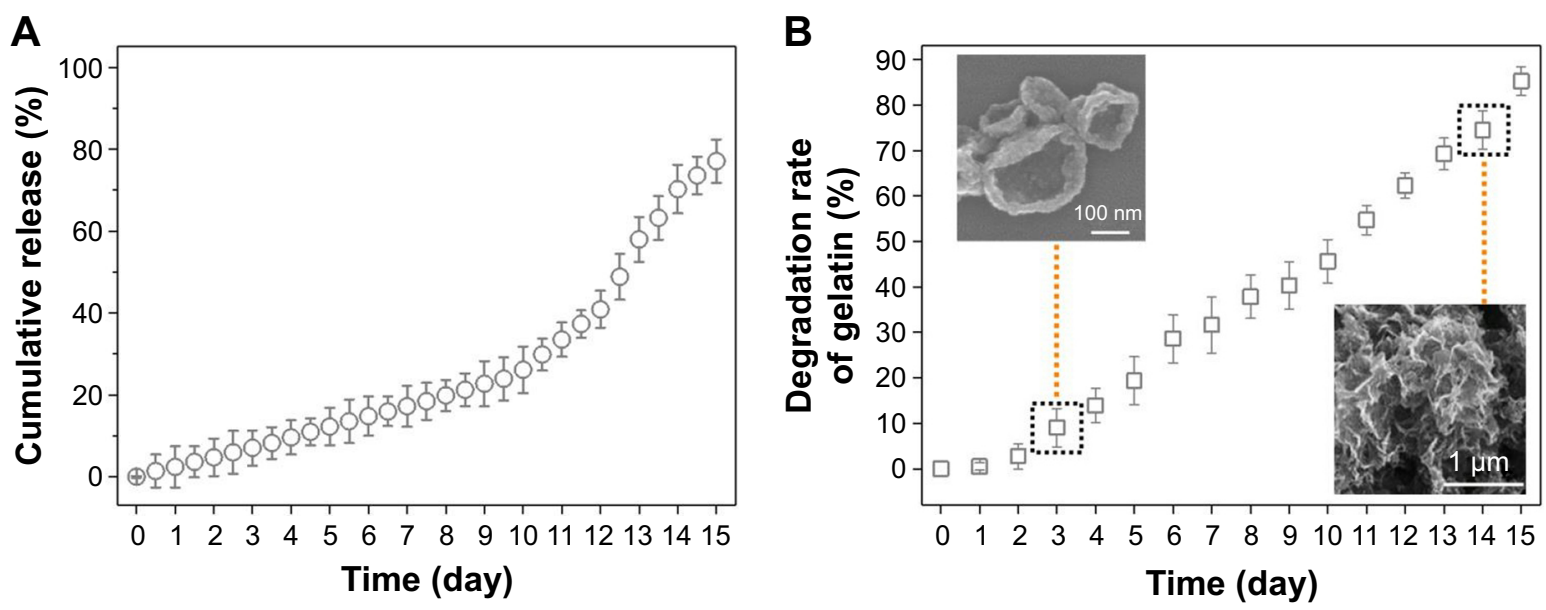

Figure 2 Degradation of MAGNCs and the release profile of TGF- $\beta$ I.

Note: (A) TGF- $\beta$ I release profiles and (B) degradation rate profiles of the MAGNCs with the insets showing the structure of TGF- $\beta$ I@MAGNCs at days 3 and I4. Abbreviations: MAGNCs, magnetic amphihilic gelatin nanocapsules; TGF- $\beta$ I, transforming growth factor- $\beta$ I; TGF- $\beta$ I@MAGNCs, TGF- $\beta$ I-loaded MAGNCs. 
A

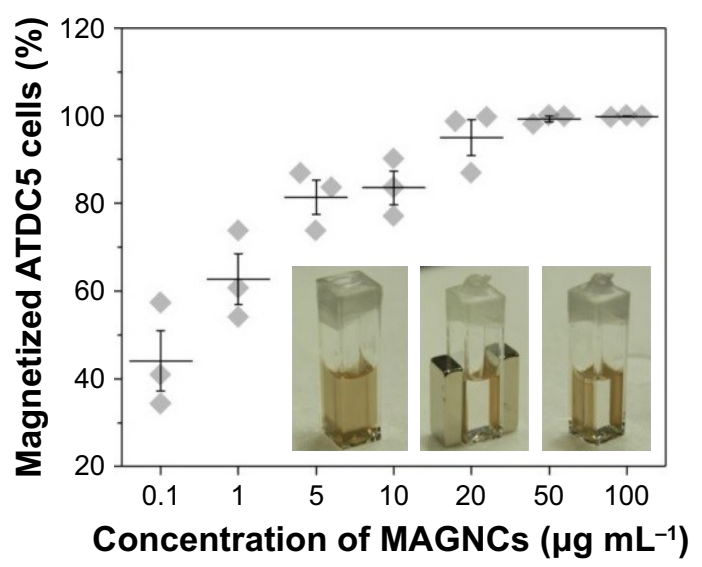

B

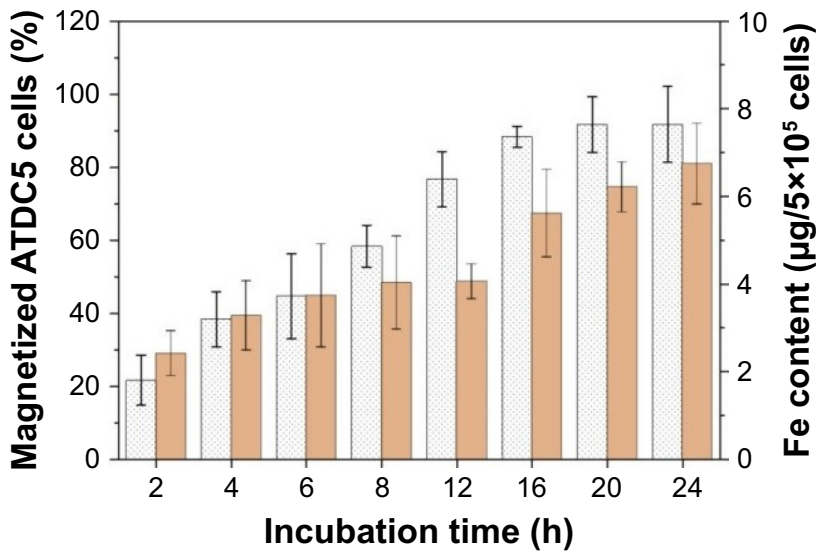

Figure 3 Magnetization of ATDC5 cells.

Notes: (A) Evaluation of the ratio of the magnetized cells after incubating ATDC5 cells with various MAGNC concentrations for $24 \mathrm{~h}$. (B) Evaluation of the magnetized cells and the cell-associated Fe content by incubating ATDC5 cells with MAGNCs $\left(20 \mu \mathrm{g} \mathrm{mL}^{-1}\right)$ for 2, 4, 6, 8, 12, 16, 20, and $24 \mathrm{~h}$.

Abbreviation: MAGNCs, magnetic amphiphilic gelatin nanocapsules.

was observed compared with $44.2 \%$ at $6 \mathrm{~h}$ incubation, indicating that the MAGNCs were mainly located in the cell membrane and saturation was temporarily reached at 6-12 h incubation. However, although Fe content further increased after $16 \mathrm{~h}$ of incubation, a slight increase in the amount of magnetized cells was observed. The results demonstrate that biocompatible MAGNCs have the ability to associate with and magnetize cells after a short incubation for further cell guiding and retention.
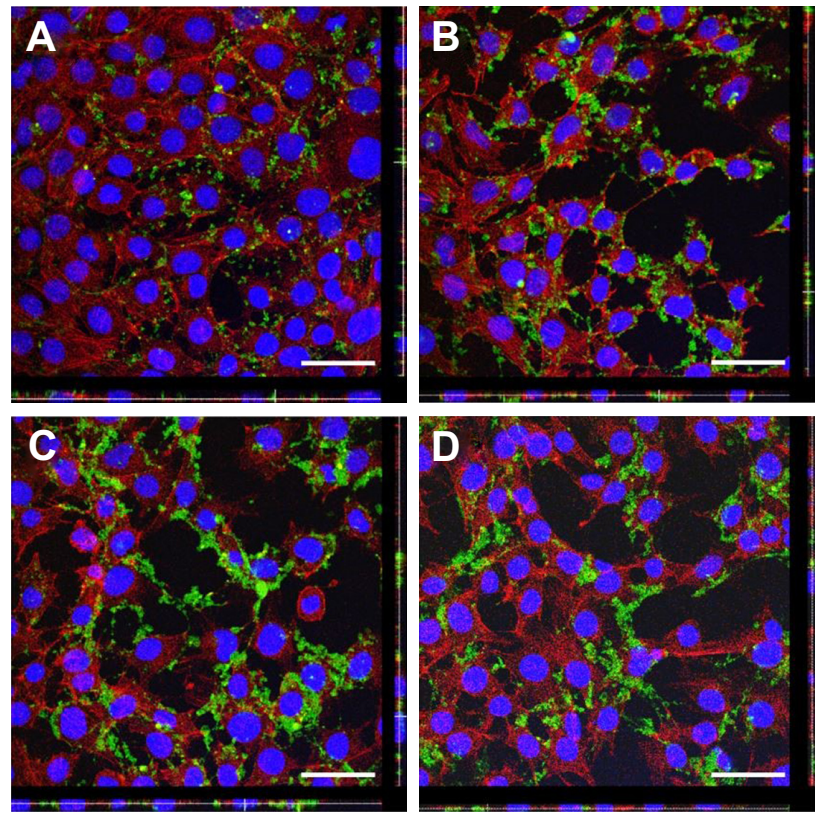

\section{Cell association of FITC-labeled MAGNCs with ATDC5}

To assess the interaction of MAGNCs with cells, ATDC5 cells were treated with FITC-labeled MAGNCs (FITC@, MAGNCs) and analyzed by fluorescence microscopy and flow cytometry. FITC@MAGNCs were detected on the ATDC5 cell membranes after $1 \mathrm{~h}$ incubation due to the RGD targeting ability (Figure 4A). We further observed rapid accumulation of MAGNCs on ATDC5 cells after $4 \mathrm{~h}$ incubation

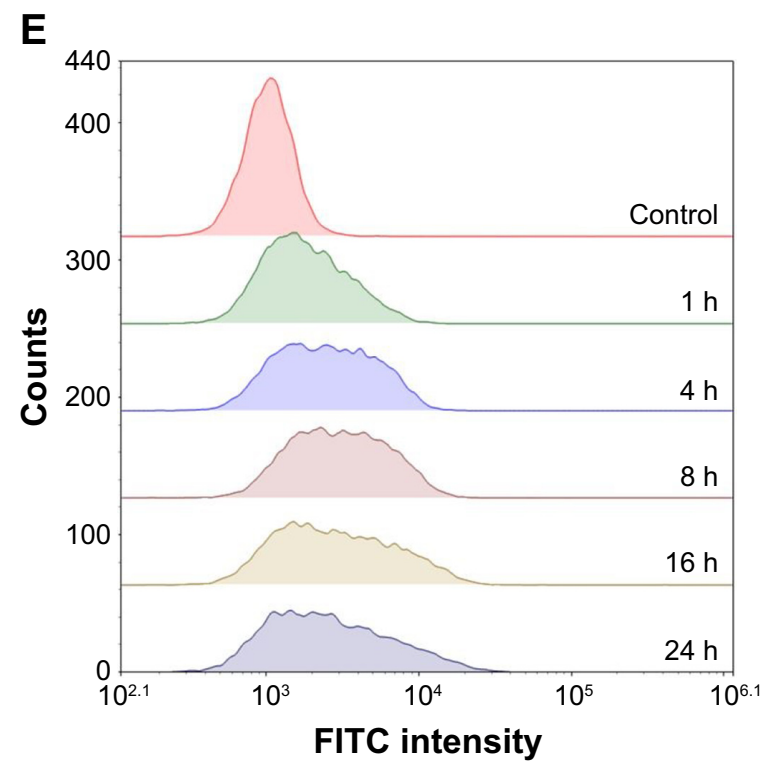

Figure 4 Cell association of MAGNCs with ATDC5 cells.

Notes: (A-D) Immunofluorescence in ATDC5 cells treated with FITC@MAGNCs for (A) I h, (B) 4 h, (C) 8 h, and (D) 24 h under confocal microscopy and (E) the flow cytometry analysis for $\mathrm{I}, 4,8,16$, and $24 \mathrm{~h}$ incubation. Scale bars $=50 \mu \mathrm{m}$.

Abbreviation: MAGNCs, magnetic amphiphilic gelatin nanocapsules. 
(Figure 4B). For 8 and $24 \mathrm{~h}$ incubation (Figure 4C and D), the FITC@MAGNCs were located at both cell membrane and cytoplasm, indicating the dynamic process of cell targeting and intracellular delivery. Flow cytometry on uptake experiment by FITC@MAGNC-treated ATDC5 cells in Figure 4E showed that the enhanced fluorescence intensity was detected at $16 \mathrm{~h}$ incubation compared to $8 \mathrm{~h}$ incubation, where the median fluorescence intensity increased 1.24-fold. After that, the distribution of fluorescence intensity was flattened especially at $24 \mathrm{~h}$. From these results, we concluded that the cell uptake behavior of nanoparticles can be considered as a subsequent 2-stage interaction. First, nanoparticles accumulated around the cells are saturated at 6-8 h. After $12 \mathrm{~h}$, the nanoparticles around or within cells are enhanced significantly, which is consistent with the result in Figure 3B.

\section{Magnetic guidance of cells}

Several earlier reports have demonstrated that the in vivo movement of cells labeled with magnetic nanoparticles can be manipulated by applying an exogenous MF. Here, as shown in Figure 5A, the translocation of ATDC5 cells, which were incubated with QD-labeled MAGNCs for $8 \mathrm{~h}$, was evaluated using an external magnet ( $\mathrm{MF}=1,000$ Gauss). As shown in Figure $5 \mathrm{~B}$ and $\mathrm{C}$, in the presence of an external magnet, the ATDC5 cells are rapidly guided toward the magnet, resulting in the formation of an area of high cell density. As shown in Figure 5D, the magnetically localized cells had large numbers of MAGNCs (red signal represented the QD in MAGNCs). The MAGNC-labeled ATDC5 cells demonstrated the magnetic capacity to be guided by an MF to achieve cell retention at the sites of the defect.

\section{Effect of MF and TGF- $\beta$ I stimuli on ATDC5 differentiation}

The complete expression of chondrogenic features in ATDC5 cells required a few weeks of ITS stimulation, so we observed differentiation with different stimuli for a 2-week duration. We performed a pretest to confirm chondrogenic differentiation of ATDC5 cells for the negative control (without TGF- $\beta 1$ ) and positive control (with TGF- $\beta 1$ ) groups. As shown in Figure S6 (Supplementary materials), the positive control group (ctrl+) showed upregulation of Col2a1 and expression of sGAG as well as collagen type II at both days 7 and 14, demonstrating chondrogenesis. Subsequently, to evaluate the combination stimuli of TGF- $\beta 1$ delivery and magnetic
A
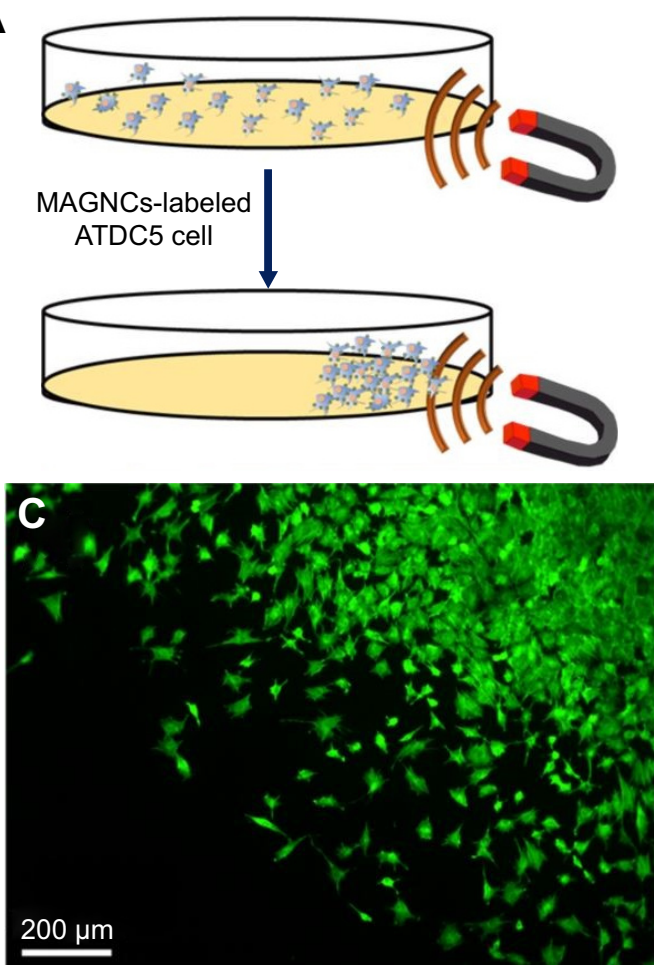
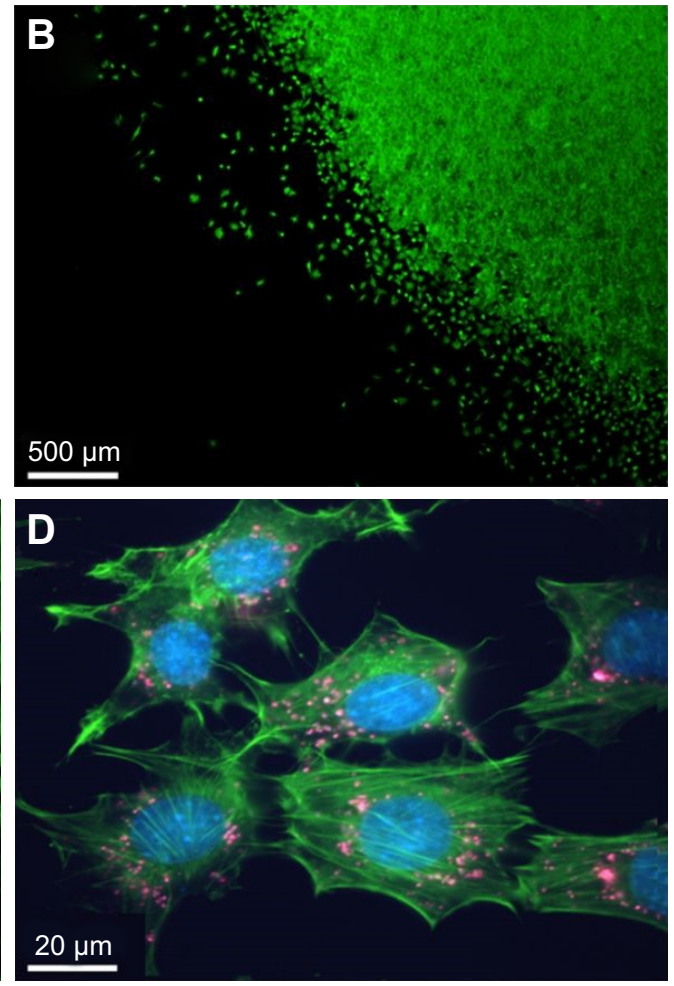

Figure 5 Cell guiding ability of MAGNC-labeled ATDC5.

Notes: (A) Illustration of the magnetic guidance of MAGNC-labeled ATDC5 cells in vitro. The cells in the area of magnetic enrichment were observed using florescence microscopy with magnitudes of (B) 4×, (C) 10×, and (D) I00×.

Abbreviation: MAGNC, magnetic amphiphilic gelatin nanocapsules. 
stimulation using MAGNCs, 6 groups including control negative, control positive, MAGNCs, TGF- $\beta 1 @ M A G N C s$, MAGNCs + M, and TGF- $\beta 1 @ M A G N C s+M$ were analyzed for response to different combinations of stimulation.

As shown in Figure 6, among the groups at 7 days, MAGNCs + M and TGF- $\beta 1 @ M A G N C s+M$ presented a relatively lower Collal expression compared with control. Moreover, stimulation by steady MF produced a significant upregulation of Col2a1 in ATDC cells treated with MAGNCs + M and TGF- $\beta 1 @ M A G N C s+M$ at day 7 , indicating that magnetic stimulation can remarkably enhance Col2al gene expression of ATDC5 cells in a short period of time. However, there was little Aggrecan expression in any of the groups.

Subsequently, at day 14, homogeneous Collal expression was observed in all groups, demonstrating the chondrogenic phenotype. However, the ATDC5 cells treated with TGF- $\beta 1$ alone showed significantly higher expression of Col2al compared with that of the control at day 7 . These results indicate that TGF- $\beta 1$ is functionalized to cells through a transmembrane pathway, and the time to activate TGF- $\beta 1$ signaling pathway to affect cell differentiation should be taken more than 7 days. In addition, it was also noted that the increase in Col2a1 gene expression from TGF- $\beta 1 @$ MAGNCs is limited as compared to that with free TGF- $\beta$ because MAGNCs are nanosize in scale and the sustained release of TGF- $\beta$ from the MAGNCs in culture medium or exocytosized by ATDC5 is not enough. This indicates that sustained release of TGF- $\beta 1$ from the MAGNCs to induce differentiation for promoting cell differentiation can be optimized by controlling the particle size and surface modification of MAGNCs.
Likewise, the MAGNCs + M-treated group showed a further increase in Col2al expression compared with TGF$\beta 1$-treated cells, indicating that a single stimulus with MF had significant impact on differentiation. Moreover, TGF- $\beta 1 @$ MAGNCs + M with a combination of stimuli demonstrated the most effective treatment, showing higher expression for both Col2al and Aggrecan compared to the other groups. Together, the results demonstrate that TGF- $\beta 1$ exhibits a long-term dominant effect on Col2al expression, while MF could induce ATDC5 differentiation in a short incubation time. As a result, the combination of a long-term stimulus from sustained release of TGF- $\beta 1$ and a continuous magnetic stimulus is the optimal strategy to achieve synergism toward chondrogenesis.

Immunofluorescence staining was further used to evaluate the intensity and expression of type II collagen at 1, 3, 5, 7, 11 , and 14 days of different stimuli. The results in Figure S7 show that both the TGF- $\beta 1$ - and TGF- $\beta 1 @$ MAGNCs + $\mathrm{M}$-treated groups had a relatively higher fluorescent intensity at day 7. Similar to the results shown in Figure 6, although the TGF- $\beta 1 @ M A G N C$-treated groups induced the formation of type II collagen (ie, 2.3-fold fluorescent intensity compared with negative control), the TGF- $\beta$-treated group was more effective, showing a 4-fold stronger fluorescent intensity compared with the negative control group at day 14 . Interestingly, the number of ATDC5 cells in the TGF- $\beta 1 @$ MAGNCs + M groups was less than that in other groups, which may be due to the "anchoring effect" of the MAGNCs by external MF on ATDC5 cells, which hindered the cell migration or extension, resulting in a relatively low number of cells. However, significant expression of type II collagen
A

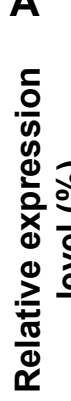

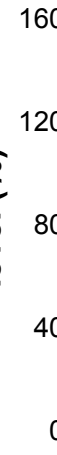
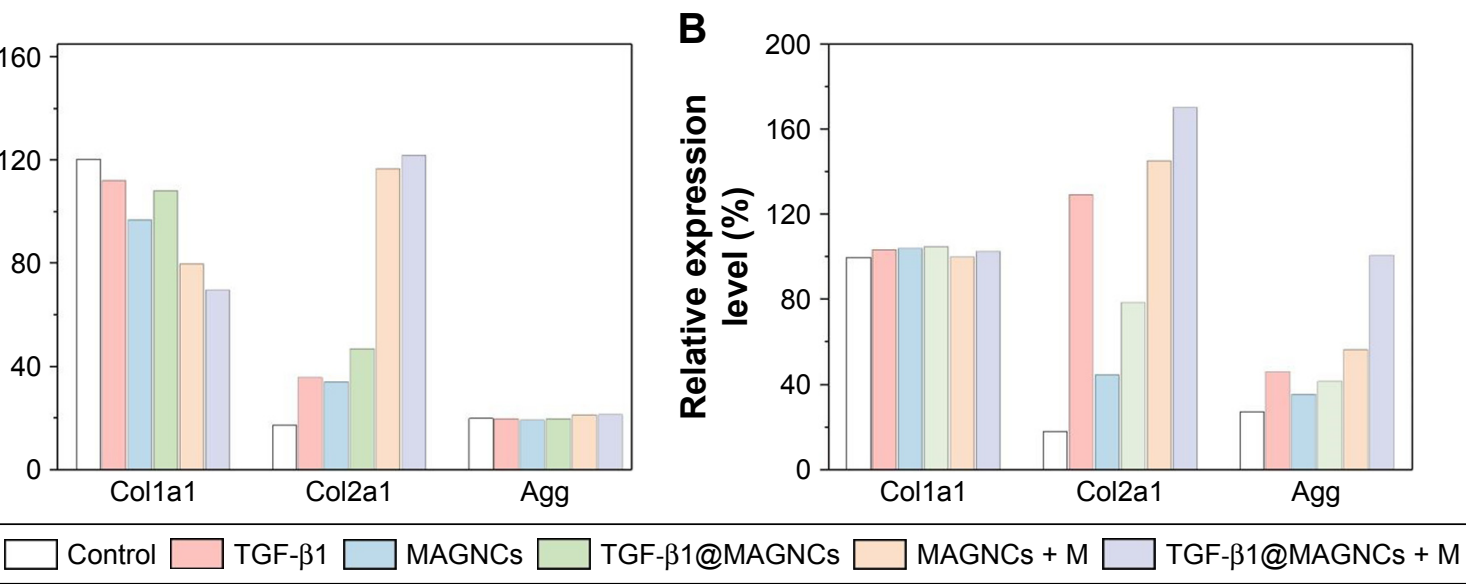

Figure 6 PCR results for Colla I, Col2a l, and Aggrecan expression.

Notes: The ATDC5 cells treated with TGF- $\beta$ I and different MAGNC formulations with/without MF were analyzed at (A) 7 and (B) 14 days.

Abbreviations: MAGNCs + M, MAGNCs with magnetic treatment; MAGNCs, magnetic amphiphilic gelatin nanocapsules; MF, magnetic field; TGF- $\beta$ I, transforming growth factor- $\beta$ I; TGF- $\beta$ I@MAGNCs + M, TGF- $\beta$ I@MAGNCs with magnetic treatment; TGF- $\beta$ I@MAGNCs, TGF- $\beta$ I-loaded MAGNCs. 
A
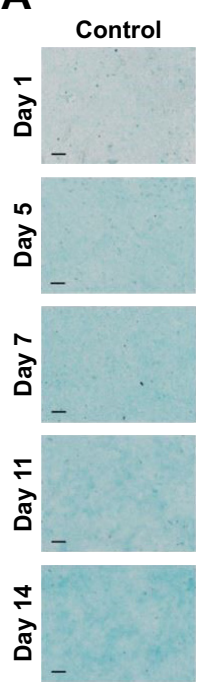
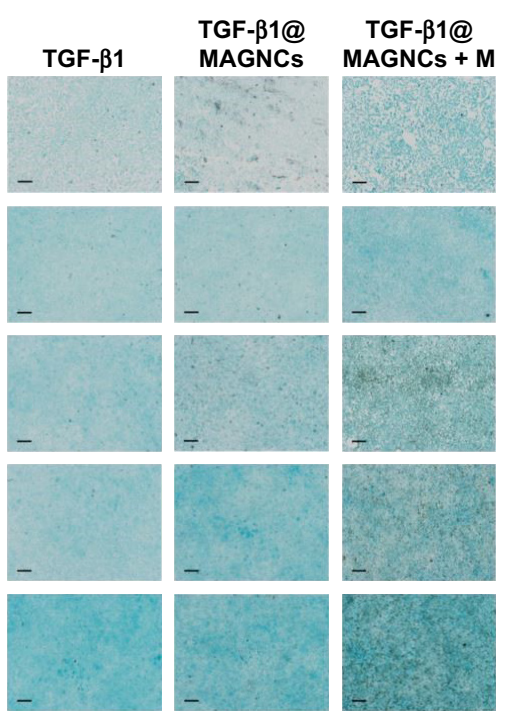

B

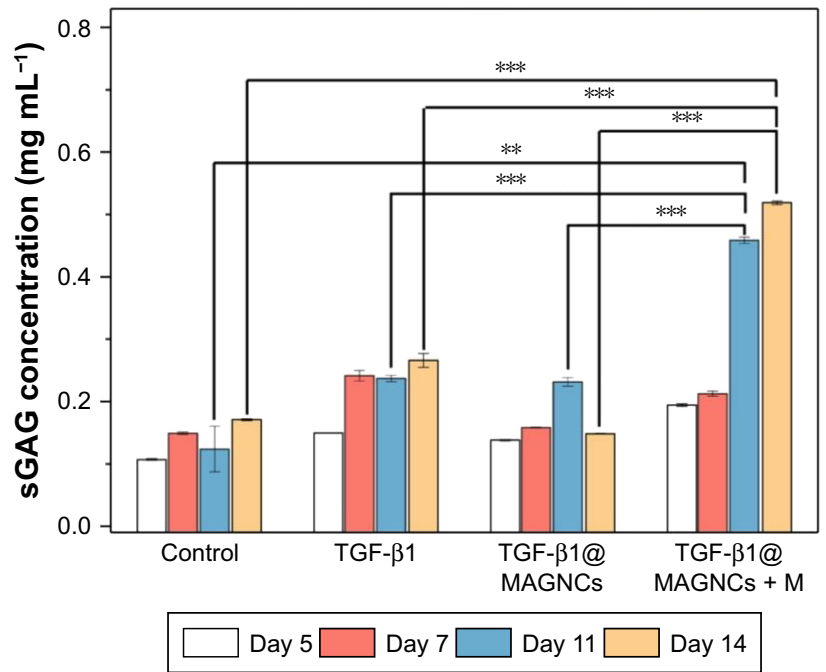

Figure 7 Evaluation for the chondrogenesis.

Notes: (A) Alcian blue staining of sGAG demonstrates the secretion concentration in ATDC5 cells under different stimuli from I to I4 days of observation (scale bars: $200 \mu \mathrm{m}$ ), and (B) Blyscan assay detects the sGAG concentration in culture medium with different stimulation from 5 to 14 days. All the results are expressed as the mean $\pm \mathrm{SD}, \mathrm{n}=3 ; * * \mathrm{P}<0.0 \mathrm{I}$ and $* * * \mathrm{P}<0.00 \mathrm{I}$.

Abbreviations: MAGNCs, magnetic amphiphilic gelatin nanocapsules; sGAG, sulfated glycosaminoglycan; TGF- $\beta$ I, transforming growth factor- $\beta$ I; TGF- $\beta$ I@MAGNCs + M, TGF- $\beta$ I@MAGNCs with magnetic treatment; TGF- $\beta$ I@MAGNCs, TGF- $\beta$ I-loaded MAGNCs.

was presented in ATDC5 cells treated with TGF- $\beta 1 @$ MAGNCs + M.

In addition to immunofluorescence staining, Alcian blue staining and Blyscan assay were also performed to assess the presence of sGAG. As shown in Figure 7A, the blue stain in the control groups increased with time because the ITS supplement in the medium also stimulates chondrogenesis. However, the TGF- $\beta 1 @$ MAGNC + M-treated group showed the highest fluorescent intensity at days 11 and 14, suggesting that chondrogenic development was more active than that in other groups (Figure 7B). Using the Blyscan assay, we quantified the sGAG concentration in the culture medium and found it was consistent with the results from Alcian blue staining, indicating that the combination of TGF- $\beta 1$ and steady MF via a single TGF- $\beta 1 @$ MAGNCs + $\mathrm{M}$ platform can achieve chondrogenesis in cell-based AC tissue regeneration.

It is worth mentioning that biomarkers such as lubricin and $\beta$-Defensin have been introduced both in vitro and in vivo to evaluate the $\mathrm{AC}$ destruction in OA..$^{29-32}$ Musumeci et $\mathrm{al}^{33}$ demonstrated, for the first time, the expression of $\beta$-defensin- 4 as an in vivo marker in chondrocytes from AC of the knee obtained from 30 patients with OA to provide an overview of the physiological processes of meniscus repair. On the other hand, a clinical study on histological analysis has revealed that the menisci derived from OA patients shows evidence of structural alterations and weak lubricin expression..$^{34}$ Therefore, there has been significant focus on novel cell-based or cell transplantation strategies in conjunction with functional materials for repair of cartilage lesions in patients with OA. If needed, biomarkers can be further evaluated to provide new insights into the physiological processes for the repair of patients with OA.

\section{Conclusion}

To overcome the obstacles of treating AC disorder, we designed a combination stimulation platform using a multifunctional protein-based TGF- $\beta 1 @ M A G N C$. With an affinity for ATDC 5 cells, TGF- $\beta 1 @$ MAGNC can magnetize ATDC5 cells and stimulate chondrogenesis using TGF- $\beta 1$ and a steady MF. The results show that TGF- $\beta 1$ treatment induces ATDC5 chondrogenesis under long-term incubation while a constant external MF can induce chondrogenic differentiation. Although the TGF- $\beta 1$ encapsulated in TGF- $\beta 1 @$ MAGNCs did not exhibit a strong positive effect on chondrogenic type II collagen expression, compared with free TGF- $\beta 1$, the TGF- $\beta 1 @ M A G N C s$ with TGF- $\beta 1$ and MF showed superior improvement in chondrogenesis compared with stimulation by any single agent. In addition, TGF- $\beta 1 @$ MAGNCs with magnetic stimulation can achieve cell retention and stronger induction of chondrogenesis, demonstrating the promise of this strategy for cell-based AC tissue repair. The study reveals that a growth factor-loaded magnetic microcarrier with biomarkers such as lubricin and $\beta$-Defensin demonstrate promising clinical potential to help in the treatment of patients with $\mathrm{OA}$ in vivo in the future. 


\section{Acknowledgment}

This work was financially supported by the Ministry of Science and Technology Republic of China (Taiwan), under Contract 102-2221-E-009-024-MY3 and 104-2314-B-214001-MY3.

\section{Disclosure}

The authors report no conflicts of interest in this work.

\section{References}

1. Huey DJ, Hu JC, Athanasiou KA. Unlike bone, cartilage regeneration remains elusive. Science. 2012;338(6109):917-921.

2. Grassel S, Lorenz J. Tissue-engineering strategies to repair chondral and osteochondral tissue in osteoarthritis: use of mesenchymal stem cells. Current Rheumatol Rep. 2014;16(10):452.

3. Schwinté P, Keller L, Eap S, Mainard D, Benkirane-Jessel N. Osteoarticular regenerative nanomedicine: advances and drawbacks in articular cartilage regeneration implants. Austin J Nanomed Nanotechnol. 2014;2(4):1025.

4. Mollon B, Kandel R, Chahal J, Theodoropoulos J. The clinical status of cartilage tissue regeneration in humans. Osteoarthritis Cartilage. 2013;21(12):1824-1833.

5. Makris EA, Gomoll AH, Malizos KN, Hu JC, Athanasiou KA. Repair and tissue engineering techniques for articular cartilage. Nat Rev Rheumatol. 2015;11(1):21-34.

6. Szychlinska MA, Castrogiovanni P, Nsir H, et al. Engineered cartilage regeneration from adipose tissue derived-mesenchymal stem cells: a morphomolecular study on osteoblast, chondrocyte and apoptosis evaluation. Exp Cell Res. 2017;357(2):222-235.

7. Musumeci G, Carnazza ML, Loreto C, Leonardi R, Loreto C. $\beta$-Defensin-4 (HBD-4) is expressed in chondrocytes derived from normal and osteoarthritic cartilage encapsulated in PEGDA scaffold. Acta Histochem. 2012;114(8):805-812.

8. Musumeci G, Castrogiovanni P, Trovato FM, et al. Physical activity ameliorates cartilage degeneration in a rat model of aging: a study on lubricin expression. Scand J Med Sci Sports. 2015;25(2):e222-e230.

9. Fortier LA, Barker JU, Strauss EJ, McCarrel TM, Cole BJ. The role of growth factors in cartilage repair. Clin Orthop Relat Res. 2011; 469(10):2706-2715.

10. Ansboro S, Hayes JS, Barron V, et al. A chondromimetic microsphere for in situ spatially controlled chondrogenic differentiation of human mesenchymal stem cells. $J$ Control Release. 2014;179:42-51.

11. Park H, Temenoff JS, Holland TA, Tabata Y, Mikos AG. Delivery of TGF- $\beta 1$ and chondrocytes via injectable, biodegradable hydrogels for cartilage tissue engineering applications. Biomaterials. 2005; 26(34):7095-7103.

12. Niu X, Feng Q, Wang M, Guo X, Zheng Q. Porous nano-HA/collagen/ PLLA scaffold containing chitosan microspheres for controlled delivery of synthetic peptide derived from BMP-2. J Control Release. 2009;134(2):111-117.

13. Bian L, Zhai DY, Tous E, Rai R, Mauck RL, Burdick JA. Enhanced MSC chondrogenesis following delivery of TGF- $\beta 3$ from alginate microspheres within hyaluronic acid hydrogels in vitro and in vivo. Biomaterials. 2011;32(27):6425-6434.

14. Lim JJ, Hammoudi TM, Bratt-Leal AM, et al. Development of nanoand microscale chondroitin sulfate particles for controlled growth factor delivery. Acta Biomater. 2011;7(3):986-995.

15. Musumeci G. The effect of mechanical loading on articular cartilage. J Funct Morphol Kinesiol. 2016;1:154-161.

16. Waldman SD, Couto DC, Grynpas MD, Pilliar RM, Kandel RA. Multiaxial mechanical stimulation of tissue engineered cartilage: review. Eur Cell Mater. 2007;13:66-73.
17. Gardner OFW, Musumeci G, Neumann AJ, et al. Asymmetrical seeding of MSCs into fibrin-poly(ester-urethane) scaffolds and its effect on mechanically induced chondrogenesis. J Tissue Eng Regen Med. 2017; 11(10):2912-2921.

18. Son B, Kim HD, Kim M, et al. Physical stimuli-induced chondrogenic differentiation of mesenchymal stem cells using magnetic nanoparticles. Adv Healthc Mater. 2015;4(9):1339-1347.

19. Elzoghby AO. Gelatin-based nanoparticles as drug and gene delivery systems: reviewing three decades of research. J Control Release. 2013; 172(3):1075-1091.

20. Yao Y, Wang Y. ATDC5: an excellent in vitro model cell line for skeletal development. J Cell Biochem. 2013;114(6):1223-1229.

21. Sun S, Zeng H, Robinson DB, et al. Monodisperse $\mathrm{MFe}_{2} \mathrm{O}_{4}(\mathrm{M}=\mathrm{Fe}$, Co, Mn) nanoparticles. J Am Chem Soc. 2004;126(1):273-279.

22. Li WM, Liu DM, Chen SY. Amphiphilically-modified gelatin nanoparticles: Self-assembly behavior, controlled biodegradability, and rapid cellular uptake for intracellular drug delivery. J Mater Chem. 2011; 21(33):12381-12388

23. Ishibashi H, Nariai Y, Kanno T, Onimaru M, Sekine J. Effects of transforming growth factor $\beta 1$ on the plasminogen activation system, collagen and integrin synthesis, and proliferation of rabbit mandibular condylar chondrocytes. Int J Oral Maxillofac Surg. 2014;43(4):470-475.

24. Han F, Adams CS, Tao Z, et al. Transforming growth factor- $\beta 1$ (TGF- $\beta 1$ ) regulates ATDC 5 chondrogenic differentiation and fibronectin isoform expression. $J$ Cell Biochem. 2005;95(4):750-762.

25. Chen J, Wang F, Zhang Y, et al. In vivo tracking of superparamagnetic iron oxide nanoparticle labeled chondrocytes in large animal model. Ann Biomed Eng. 2012;40(12):2568-2578.

26. Murphy MK, Huey DJ, Hu JC, Athanasiou KA. TGF- $\beta 1$, GDF-5, and BMP-2 stimulation induces chondrogenesis in expanded human articular chondrocytes and marrow-derived stromal cells. Stem Cells. 2015;33(3):762-773.

27. Santoro M, Tatara AM, Mikos AG. Gelatin carriers for drug and cell delivery in tissue engineering. $J$ Control Release. 2014;190:210-218.

28. Hoch E, Schuh C, Hirth T, Tovar GE, Borchers K. Stiff gelatin hydrogels can be photo-chemically synthesized from low viscous gelatin solutions using molecularly functionalized gelatin with a high degree of methacrylation. J Mater Sci Mater Med. 2012;23(11):2607-2617.

29. Musumeci G, Castrogiovanni P, Mazzone V, Szychlinska MA, Castorina S, Loreto C. Histochemistry as a unique approach for investigating normal and osteoarthritic cartilage. Eur J Histochem. 2014; 58(2):2371.

30. Musumeci G, Castrogiovanni P, Loreto C, Castorina S, Pichler K, Weinberg AM. Post-traumatic caspase-3 expression in the adjacent areas of growth plate injury site: a morphological study. Int J Mol Sci. 2013;14(8):15767-15784.

31. Jay GD, Waller KA. The biology of lubricin: near frictionless joint motion. Matrix Biol. 2014;39:17-24.

32. Szychlinska MA, Leonardi R, Al-Qahtani M, Mobasheri A, Musumeci G. Altered joint tribology in osteoarthritis: reduced lubricin synthesis due to the inflammatory process. New horizons for therapeutic approaches. Ann Phys Rehabil Med. 2016;59(3):149-156.

33. Musumeci G, Carnazza ML, Leonardi R, Loreto C. Expression of $\beta$-defensin-4 in "an in vivo and ex vivo model" of human osteoarthritic knee meniscus. Knee Surg Sports Traumatol Arthrosc. 2012;20(2):216-222.

34. Musumeci G, Trovato FM, Loreto C, et al. Lubricin expression in human osteoarthritic knee meniscus and synovial fluid: a morphological, immunohistochemical and biochemical study. Acta Histochem. 2014;116(5):965-972.

35. Biocolor. BlyscanTM Sulfated glycosaminoglycan assay. Available from: https://www.biocolor.co.uk/site/wp-content/uploads/2016/04/ blyscan-assay-manual-1.pdf. Accessed May 4, 2018.

36. Applied Biosystems; Life Technologies. TaqMan ${ }^{\circledR}$ gene expression assays protocol. Available from: https://tools.thermofisher.com/content/ sfs/manuals/cms_041280.pdf. Accessed May 4, 2018. 
International Journal of Nanomedicine

Dovepress

\section{Publish your work in this journal}

The International Journal of Nanomedicine is an international, peerreviewed journal focusing on the application of nanotechnology in diagnostics, therapeutics, and drug delivery systems throughout the biomedical field. This journal is indexed on PubMed Central,

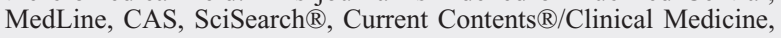

Journal Citation Reports/Science Edition, EMBase, Scopus and the Elsevier Bibliographic databases. The manuscript management system is completely online and includes a very quick and fair peer-review system, which is all easy to use. Visit http://www.dovepress.com/ testimonials.php to read real quotes from published authors.

Submit your manuscript here: http://www.dovepress.com/international-journal-of-nanomedicine-journal 